\title{
Analyzing People's Behavior towards Minimizing Municipal Solid Waste in Bechar City in Algeria
}

\author{
Bouanini Samiha \\ Resources and Environmental Management \\ International Exchange College, Nanchang University, China \\ E-mail:bs_miha@yahoo.com
}

\section{Doi:10.5901/jesr.2014.v4n1p317}

\begin{abstract}
We are afraid to breathe the air because we don't know what chemicals are in it, we make so much waste. Therefore, we should find solutions to reduce this waste and we should fight to solve our future. Most of waste can be treated by incineration, composting or landfill. However, all these methods cause air, water and soil pollution, which is harmful to human health, plants, and animals. Therefore, developed countries promote waste prevention reduction, reuse, and recycling. The quantity of municipal solid waste in Bechar city is increasing every year, and this is due to the lack of people's participation in reduce, reuse and recycle. This research analyzes people's behavior towards reducing municipal solid waste in Bechar city in Algeria. Firstly, it depended on the collection of information for the period 2006-2013 from the Environmental Directorate of Bechar city. Secondly, it used a quantitative analysis based on a survey which has addressed randomly 400 residents in Bechar city from September 2013 to November 2013, but only 312 were available to analyze. Thirdly, it used "SPAD" software as a qualitative method to analyze the database by factorial analysis of multiple correspondences "FAMC" method. And finally, it included that people help for reducing the use of plastic bags, but they don't participate in reusing principal. In addition, there is a lack in knowledge and culture of recyclable products. And people in their majorities were affected by both cultural and political factors to minimize waste, and the rest didn't comply with these factors.
\end{abstract}

Keywords: Minimization, Municipal Solid Waste, Bechar City, Algeria, Survey, Cultural, Political, Factors.

\section{Introduction}

We are afraid to breathe the air because we don't know what chemicals are in it, we make so much waste, we buy products and throw it away. So we should find solutions to reduce this waste and we should fight to solve our future. The environmental concern is very important because the interest of a clean environment is among the most important pillars of sustainable development. Therefore, the amount of waste we produce is the result of our unsustainable lifestyle. Most of waste can be treated by incineration, composting or landfill. However, all these methods cause air, water and soil pollution, which is harmful to human health, plants, and animals. Therefore, developed countries promote waste prevention reduction, reuse, and recycling. This research analyzes people's behavior towards reducing municipal solid waste in Bechar city in Algeria. This city is situated in south west of the country Algeria with area of $161.400 \mathrm{Km}^{2}$; it is $6,77 \%$ of the national territory. It has reached a population of 197.753 people in 2012. And it ranks the $6^{\text {th }}$ compared to all cities in Algeria. The reasons behind this study are to analyze the behavior of people towards reducing, reusing and recycling. As well as gathering information to reach real and realistic conclusions. Moreover, there is another reason which is trying to make people aware and make them thinking about the negative effects of the increasing waste. And create some incentives to push people to reduce waste as much as possible. The finding of this research can be different because it focused on the compositions of municipal solid waste and the ways of treating these wastes, moreover, the region "Bechar" that has been chosen was not analyzed previously by researchers. For that, this paper gives firstly this brief introduction, and secondly, it discusses the literature review about this topic and shows some previous studies in same topic for other regions. Thirdly, it explains the methodology which is used to analyze data. Fourthly, this study discusses the finding to reach some concluding remarks.

\section{Literature Review}

Over the last decade, environmental issues have become increasingly more important world-wide (Eberhard \& Hans, 2002), and municipal solid waste generation is closely linked to population, urbanization and affluence (Dong et al, 2010, 
and Guilberto and Shigefumi, 2010). There are several literatures about municipal solid waste management in several countries in the world, and the good examples of municipal solid waste management are in developed countries such as Germany, France, Japan, and United States. And among the literatures there is Chung and Poon (1994) who analyzed Hong Kong citizens' attitude towards waste recycling and waste minimization. And they found that Hong Kong people generally support waste recycling and minimization measures. Wenke et al (2002) participated with a paper for the seminar on household waste management entitled "capacity building on European Community's Environmental Policy". They pointed the EU waste policy and challenges for regional and local authorities including the municipal solid waste management. Ulrich and Cees (2002) viewed municipal waste management in some European countries including the current situation of municipal solid waste and the general overview of municipal solid waste. Moreover, in 2005, Jasem M. Alhumoud showed the recycling of municipal solid waste in the Gulf co-operation council, and he indicated ways that can help to promote recycling and he provided strategies for developing the most effective recycling marketing program considerations and regional co-ordination options. Martin et al (2006) analyzed householders' attitudes toward recycling in England, and they found that householders are very willing to participate in recycling. The paper of Itaru and Vivian (2007) was among the reviews about municipal solid waste management in Japan. Hongpin et al (2009) characterized the recyclable resource recycling system according to a survey in Suzhou city in China, and they reviewed the strategy and policies for promoting and regulating recycling. In addition, Sefouhi et al (2010) pointed trends and problems of municipal solid waste management in Batna city in Algeria and showed the prospects for a sustainable development. Fares Masdor (2010) showed the importance of government intervention in protecting the environment through environmental taxation, and he discussed the concept of the environment, the relationship of the environment with the economy, the risk of environmental contamination and environmental pollution in the Arab World. Furthermore, Imad A. Khatib (2011) discussed in the third chapter of his book "integrated waste management" the municipal solid waste management in developing countries including the future challenges, the possible opportunities and the integrated sustainable solid waste management. In 2013, Bouanini. S, analyzed how the 3R principle (reduce, reuse and recycle) can help to achieve sustainable development. And she depended on a survey in a university environment in China in order to evaluate and analyze people's behavior and willingness to participate in the $3 R$ principle. Thus, the results showed that although the analyzed sample was educated people but there was a lack in the participation of the $3 R$ principle. As well as there was a lack in environmental knowledge.

Through the previous studies it is noted that there are very few researchers who have analyzed the status of solid waste management in Algeria. And there is no previous study about analyzing people's behavior towards municipal solid waste management in Bechar city in Algeria.

\subsection{Managing Municipal Solid Waste in Bechar City in Algeria}

Municipal solid waste is the general waste collected by municipalities which is generated mainly by households, commercial activities and street-sweeping, as well as construction and demolition debris (Martin Medina, 2010, Linda et al, 2003, Olar Zerbock and M.S. Candidate, 2003, and Guilberto and Shigefumi, 2010). In general, municipal solid waste is composed of three groups of materials: organic waste (kitchen, garden waste, etc), non-recyclable inorganic waste (coal ash, cinder, dust, etc), and recyclable waste (paper, plastics, glass, metal, etc) (Dong et. al, 2010).

The quantity of municipal solid waste in Bechar city is increasing every year, According to the Environmental Directorate of Bechar city, in 2012, the quantity of municipal solid waste produced in Bechar city was 138,43 (ton per day) and 50.526,95 (ton per year). The figure "1" bellow shows the quantities of municipal solid waste in Bechar city from 2006 to 2012.

Figure 1: the Quantity of Municipal Solid Waste in Bechar City for the Period 2006-2012

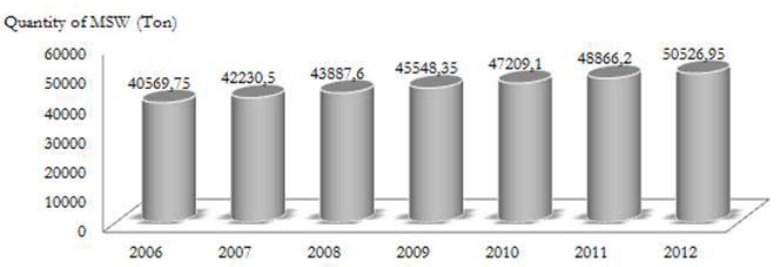

Source: Environmental Directorate of Bechar city 
The municipal solid waste in Bechar city or in Algeria as a whole contains a high proportion of Organic, plastic, and paper/cardboard. However, glass and metal make very low proportions (Kehila et. al, 2010). The following figure "2" and figure "3" show respectively the constituent ratios of municipal solid waste in Algeria and in Bechar city for 2009.

Figure 2: Algerian MSW in 2009

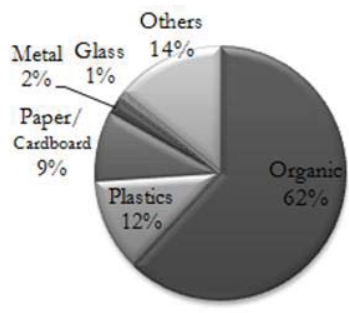

Source: Kehila et. al, 2010

Figure 3: MSW of Bechar City in 2009

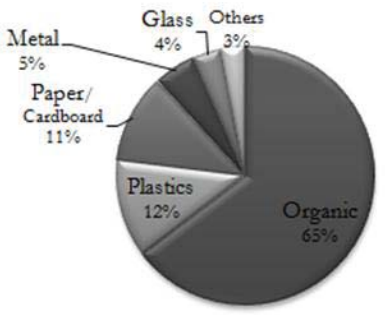

\section{Source: Environmental Directorate of Bechar City}

In 2009, the quantity of municipal solid waste generated in Algeria was estimated at 8,5 million tons/year. And each Algerian in urban areas generates about $0,7 \mathrm{~kg}$ of solid waste daily (Kehila et al, 2010).

Most of waste can be treated by incineration, composting or landfill. However, all these methods cause air, water and soil pollution, which is harmful to human health, plants, and animals. Therefore, developed countries promote waste prevention reduction, reuse, and recycling. The first step in waste management is to try and prevent the generation of waste by reducing at source the waste produced. This is the prevention principal "avoidance of waste" (N.O. Adedipe et. al, 2005, and Bhoj \& Bounsouk, 2005). According to the Federal Ministry for Economic Cooperation and Development (1996), the production of waste shall be regulated in only through quantitative limits. It is preferable to reduce generally the quantities of waste by different waste management measures, for example the promotion of recycling, deposit system, etc. An example in developing countries, such as in Algeria, refillable glass bottles are still widely used, and families routinely take the empty bottles to grocery stores when they purchase beverages. If someone doesn't bring an empty bottle when purchasing a beverage in a refillable bottle, must pay a deposit equivalent to the cost of the bottle. This encourages the return of reusable bottles which is in parallel encouraging the reuse principle. Recently, repairing furniture, bicycles etc..., is often more expensive than buying new products. In many countries reuse centers have been established. These centers aim to break the short product to waste cycle extending the life of the products through repairing them and selling them at a low price. The reuse centers can also be used as means of creating employment for people with problems in entering the job markets or suffering from long term unemployment. An example, in Nanchang (Jiangxi province in China) the government provides a big and clean center for second hand products such as refrigerators, chairs, desks, TVs etc... to encourage the reuse policy (Bouanini. S, 2012). Currently, it has spread some stores of second hand products in Bechar, and these stores are named as "Remember and Order". In Algeria there are only some small shops for second hand products, but unfortunately, there are no reuse centers.

In 2002, $2 \%$ of the Algerian municipal solid waste was recycled (METAP, 2003). Afterwards, that percentage has risen to 4-5\% in 2009 (Kehila et. al, 2010). And the recycling capacity is shown in the table "1". Recycling in Algeria depends more on paper then plastics and metals. However, plastics represent high percentage than papers (in figure 2 and figure 3). This shows that there is a percentage of plastic which is not exploited in recycling. 
Table 1 Recycling Capacity

\begin{tabular}{cc}
\hline types of waste & quantity (tons/year) \\
\hline Paper & 385.000 \\
\hline plastic & 130.000 \\
\hline metals & 100.000 \\
\hline glass & 50.000 \\
\hline various materials & 95.000 \\
\hline total & 760.000 \\
\hline
\end{tabular}

Source: Boukelia and Mecibah, 2012

In 2002, $1 \%$ of municipal solid waste was composted in Algeria (METAP, 2003). However, this ratio decreased to $0 \%$ in 2009 (Kehila et. al, 2010). Therefore, there is almost non-existent culture of composting in Algeria. There is 30\% of burned waste in open air in public dumps or municipal uncontrolled ones in Algeria (Boukelia and Mecibah, 2012). In Algeria $15 \%$ of the municipal solid waste was send to landfill in 2009. The Algerian government is seeking to achieve the "Green Economy"; for that, in August 2013, it opened a new burial technical center which is the largest one in Algeria with capacity of 20 million tons yearly. There are more than 3.000 uncontrolled dumps throughout the country, occupying an area of more than 150.000 hectares (Kehila et. al, 2010). And unfortunately there is no recycling center in Bechar city. The following figure "4" shows the percentages of the final destination of municipal solid waste in Algeria.

Figure 4: Final Destination of Municipal Solid Waste (Source: Kehila et. al, 2010).

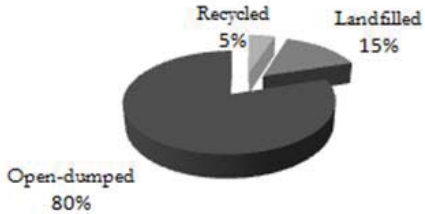

\subsection{Algerian Legislations for Municipal Solid Waste}

Since 2002, Algeria sought to create a financial action to fight pollution and minimize it, for that it issued tax act including the collection of municipal solid waste management (kamel. R, 2007). According to the Environmental Directorate of Bechar city, tax garbage removal has been significantly upgraded by Law $n^{\circ}: 01-21$ in December 22, 2001, and it applies annually fees collection of households for the benefit of municipalities where there is domestic waste collection service, based on all property. The amounts of this tax are as follow:

Table 2: Tax on the Collection of Household Waste

\begin{tabular}{cl}
\hline amounts (Algerian Dinar) & \multicolumn{1}{c}{ Source } \\
\hline $500-1000$ & Residential Use (Household Dwelling) \\
\hline $1,000-10,000$ & Commercial Use and Professional \& Vocational or something like that \\
\hline $5,000-20,000$ & Land predisposing to establish camps \\
\hline $10,000-100,000$ & $\begin{array}{l}\text { Industrial Use, Commercial Use, and Craft Producing Larger Quantities } \\
\text { of Waste than those mentioned above }\end{array}$ \\
\hline
\end{tabular}

Source: Michel et. al, 2003

Municipal Solid Waste Management National Program (PROGDEM) which is launched in 2002 has already made possible development of many projects (municipalities' master schemes, landfills, sorting centers, etc.). Algerian government has created some laws and executive decrees to manage municipal solid waste appropriately. And the table "3" bellow shows more information. 
Table 3: Algerian Legislative Laws for Municipal Solid Waste Management

\begin{tabular}{ll}
\hline \multicolumn{1}{l}{ laws and executive decrees } & \\
\hline law No.01-19 & The management, control and disposal of waste. \\
\hline Law No: 01-21 & Tax garbage removal \\
\hline law No.03-10 & The protection of the environment in the context of sustainable development. \\
\hline executive decree No.02-175 & The creation of the national waste agency ( AND) \\
\hline executive decree No.04-410 & $\begin{array}{l}\text { The general rules for the development and operation of waste treatment } \\
\text { facilities and the admission of such waste at these facilities. }\end{array}$ \\
\hline executive decree No.07-205 & $\begin{array}{l}\text { The modalities and procedures for the preparation, publication and revision of } \\
\text { the scheme of municipal household and similar waste management }\end{array}$ \\
\hline executive decree No.02-372 & Packaging waste \\
\hline executive decree04-199 & $\begin{array}{l}\text { The modalities for the establishment, organization, operation and financing of } \\
\text { the public system of treatment and recovery of packaging waste. }\end{array}$ \\
\hline
\end{tabular}

Source: Kehila et. al, 2010

\section{Research Methodology}

In order to analyze people's behavior towards minimizing municipal solid waste in Bechar city, this research firstly depended on the collection of information for the period 2006-2013 from the Environmental Directorate of Bechar city.

In addition, for following a quantitative analysis, this study based on a questionnaire used in the previous research of Bouanini. S (2013), but this questionnaire was improved by adding some other questions and editing some of them. This questionnaire is composed of several questions concerning reduce, reuse and recycle. And there are some questions about different ways to manage waste and other questions related to environmental policies and incentives. This survey has addressed randomly 400 residents in Bechar city from September 2013 to November 2013, but only 312 were available to analyze. This study used a descriptive analysis through using SPSS statistics 20 software.

Moreover, this study used "SPAD" software as a qualitative method to analyze the database by factorial analysis of multiple correspondences "FAMC" method.

\section{Findings and Discussion}

\subsection{Quantitative Analysis}

After collecting the questionnaire from the sample studied, it has found that the survey has addressed $42,3 \%$ of people between $15-30$ years old, 37,2\% of them were between $31-45$ years old, and 20,5\% of the people were more than 46 years old.

According to the results showed in the figure " 5 " bellow, people help for reducing the use of plastic bags because most of them carry their own bag when they go to the market for purchasing. And 59\% of them agree with the policy of paying for plastic bag, and they suggested replacing plastic bags with paper bags; this means that people are aware about the negative effects of using the plastic bags and they agree to reduce the use of these bags. However, people don't like to buy second hand products, and they are only willing to repair their commodity and use it again. Therefore, in this case they don't participate in reusing principal. In addition, there is a lack in knowledge and culture of recyclable products, because only $46,2 \%$ of people who are willing to buy recyclable products. And most of the people think that these are average products. Moreover, $78,2 \%$ are willing to pay tax for waste in the case if there were stringent monitoring to pay this tax.

Figure 5: People's Participation in Reduce, Reuse and Recycle

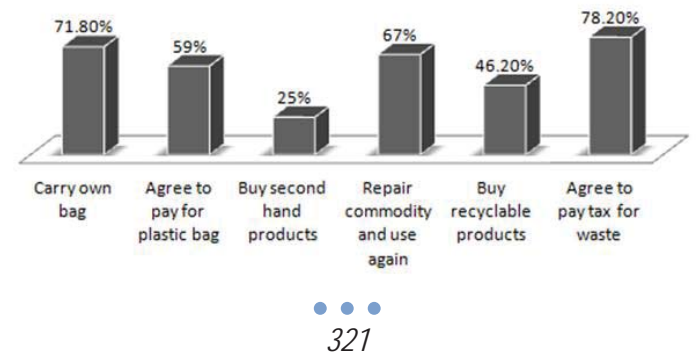


According to the survey (see figure "6" about people's knowledge and culture about waste minimization), 89,10\% of the sample analyzed watched an environmental education program, and most of them are aware about the negative effects of waste. However, only $58,30 \%$ of them think about a healthy way to get rid of waste. Most of them have proposed to provide more awareness programs and develop laws to pay a tax for each of throwing waste in public places. And encourage the exploitation of waste and turn it into organic fertilizer for farmland. As well as encouraging incineration to produce energy and promote recycling by facilitating the operations of waste sorting and create factories for recycling in Bechar city. In addition, they suggested providing garbage containers in all neighborhoods with the allocation of special containers for recyclable materials and other for non-recyclable materials, and so as to facilitate the separation process from the source and thus facilitate the recycling process.

Figure 6: People's Knowledge and Culture about Waste Minimization

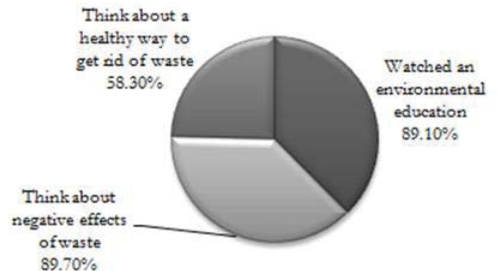

Through analyzing the nature of the factors that may motivate people to reduce waste, the results showed that $45,50 \%$ were cultural factors, $27,60 \%$ were political factors, and others factors such as religious, social and cultural. The figure "7" bellow shows more details about the nature of the factors that may motivate people to reduce waste. Therefore, the culture and knowledge play a good role to push people for waste minimization. For that it is better to provide more environmental programs for increasing people's awareness about waste minimization. As well as government may play an important role for motivating people to reduce waste buy creating some taxes for waste minimization. Moreover, the religion of this country prompts them to clean and preserve the environment.

Figure 7: The Nature of the Factors that may Motivate People to Reduce Waste

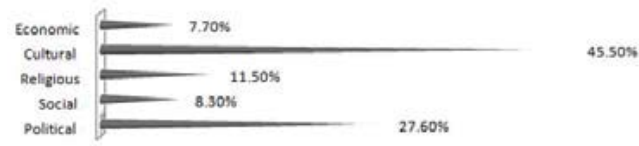

\subsection{Factorial Analyses of Multiple Correspondences}

Factor analysis applied to the results of the survey focused on 300 residents, which has allowed to put together a typological classification description of factorial axes. Factor 1 contains two major trends to know (good concern, very little concern); the factor 2 includes two reasons for waste minimization (cultural and political).

Figure 8: Factorial Analyses of Multiple Correspondences

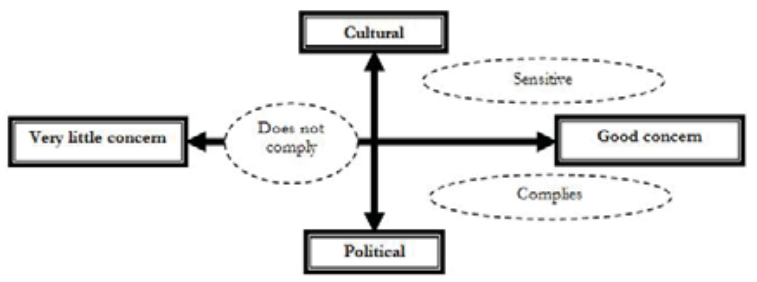

From this typology, the results could develop a new typological classification by which people in their majorities were affected by both cultural and political factors. And the rest didn't comply with these factors. 
Figure 9: Factorial Analyses of Multiple Correspondences for the Sample Analyzed

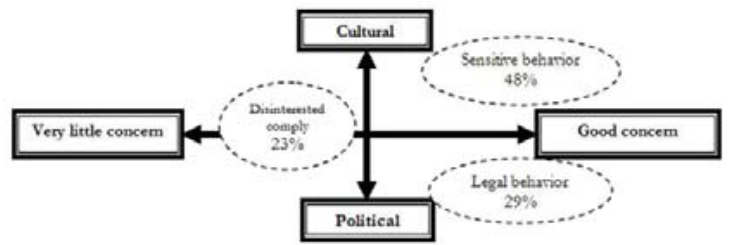

\section{Concluding Remarks}

We may influence the environment positively or negatively because we are all relate to the environment. However, we can also provide the protection of the environment at the same time. The quantity of municipal solid waste in Bechar city is increasing every year, and this is due to the lack of people's participation in reduce, reuse and recycle.

The most important factor that can help to protect the environment, as well as encouraging waste minimization is the education. Through formal education starting with kindergarten to primary schools, middle schools, high schools, and universities. Although, the environmental directorate in Bechar city is organizing an educational programs in schools, but it still needs some improvements.

The municipalities charge fees for waste collection but it doesn't charge for waste disposal. However, in reality disposal requires more technical expertise and efforts. Therefore, applying disposal fees can encourage people to minimize waste generated. And government should develop laws to pay a tax for each of throwing waste in public places because this can create unpleasant odor and unattractive appearance of piles of uncollected solid waste along streets all those can discourage tourism. Especially this city has many touristic places that attract people from worldwide, so it must preserve a clean environment to maintain the value of tourism in this city.

Therefore, municipalities should provide waste bins conveniently placed for the people to deposit waste. However, people should be aware to keep these waste bins safety. And it is better to provide garbage containers in all neighborhoods with the allocation of special containers for recyclable materials and other for non-recyclable materials, and so as to facilitate the separation process from the source and thus facilitate the recycling process. Moreover, the government should promote recycling by facilitating the operations of waste sorting and create factories for recycling in Bechar city.

For encouraging reuse principle, Algerian government should consider establishing reuse centers in each city, and it should encourage also the exploitation of waste and turn it into organic fertilizer for farmland. As well as government should encourage incineration to produce energy.

This research has faced some limitations, such as the limited information about the final destination of municipal solid waste in Bechar city. In addition, there were some difficulties to fill the questionnaire because some people rejected to fill it, so we couldn't collect more than 312 views. And this is due to the lack of knowledge concerning the importance of a survey.

\section{References}

Bhoj Raj Khanal and Bounsouk Souksavath, 2005, Environmental Management Measures and Current Practices in Solid Waste Management: A Case Study From Vientiane, Lao People's Democratic Republic, Greater Mekong Subregion Academic and Research Network "GMSARN", Vol: 4, No: 1, PP. 5-19

Bouanini Samiha, 2012, Assessing the Management of Municipal Solid Waste for Well-Being Fulfillment in Algeria, Ro'a Iktissadia, No: 3, PP. 272- 290

Bouanini Samiha, 2013, the Importance of the 3R Principle of Municipal Solid Waste Management for Achieving Sustainable Development, Mediterranean Journal of Social Sciences, Vol: 4, No: 3, PP. 129- 135

Boukelia Taqiy Eddine and Mecibah Med Salah, 2012, Solid Waste as Renewable Source of Energy: Current and Future Possibility in Algeria, International Journal of Energy and Environmental Engineering, a Springer Open Journal, 3:17, PP. 6-9

Chung S. S, and Poon C. S, 1994, Hong Kong Citizens' Attitude towards Waste Recycling and Waste Minimization Measures, Resources, Conservation and Recycling, Vol: 10, No: 4, PP: 377- 400.

Dong Qing Zhang, Soon Keat Tan, and Rechard M. Gersberg, 2010, Municipal Solid Waste Management in China: Status, Problems and Challenges, Journal of Environmental Management, Vol: 91, PP: 1623-1633.

Eberhard Seidel and Hans J. Thamhain, 2002, Managing Environmental Quality at the Enterprise: the Role of Project Management, 
Journal of Environ Eng Policy, Vol: 3, PP.19-32

Fares Masdor, the Importance of the Government Intervention in Protecting the Environment through Environmental Taxation, Researcher Journal, N: 7, PP:345- 351

Federal Ministry for Economic Cooperation and Développement, 1996, Manuel sur l'environnement, documentation pour l'étude et l'évaluation des effets sur l'environnement, volume 3, catalogue des normes antipollution, (French version) Publisher by vieweg, Deutschland

Guilberto Borongan and Shigefumi Okumura, 2010, Municipal Waste Management Report: Status-Quo and Issues in South East and East Asian Countries, Copyright VAIT/UNEP Regional Resource Center for Asia and the Pacific, United Nations Environment Programme, Thailand, PP.1-43

Hong Pin Mo, Zongguo Wen, and Jining Chen, 2009, China's Recyclable Resources Recycling System and Policy: A Case Study in Suzhou, Resources, Conservation and Recycling, Vol: 53, No: 7, PP: 409- 419.

Imad A. Khatib, 2011, chapter 3 Municipal Solid Waste Management in Developing Countries: Future Challenges and Possible Opportunities, integrated waste management, vol: 2, InTech Publisher

Itaru Okuda \& Vivian E, Thomson, 2007, 'Regionalization of municipal solid waste management in Japan: balancing the proximity principle with economic efficiency', Environmental Management, vol. 40, pp. 12-19

Jasem M. Alhumoud, 2005, Municipal Solid Waste Recycling in the Gulf Co-Operation Council, Resources, Conservation and Recycling, Vol: 45, No: 2, PP: 142- 158.

Kamel razik, 2007, the Role of the State in Protecting the Environment, El-Bahith Review, No: 5, PP.95-105

Kehila Youcef, SWEEP-Net, and Gourine Lazhari, 2010, Country Report on the Solid Waste Management in Algeria, the Regional Solid Waste Exchange of Information and Expertise Network in Mashreq and Maghreb Countries SWEEP-Net

Linda Tietjen, Débora Bossemeyer, and Noel McIntosh, 2003, Infection Prevention Guidelines for Healthcare Facilities with Limited Resources, Eight: Waste Management, JHPIEGO, USA, PP: 105-118

Martin Medina, 2010, Solid Waste, Poverty and the Environment in Developing Country Cities, Challenges and Opportunities, Working Paper No. 2010/23, Copyright of United Nations University and World Institute For Development Economics Research, PP: 1-13

Martin M, Williams I. D, and Clark M, 2006, Social, Cultural and Structural Influences on Household Waste Recycling, Vol: 48, No: 4, PP: 357-395

Mediterranean Environmental Technical Assistance Program "METAP", 2003, Washington, USA

Michel Lazare, Philippe Callier, Khanjar, Wabel Abdallah and Taline Koranchelian, 2003, Algeria: Selected Issues and Statistical Appendix, International Monetary Fund Country Report, No: 03/69, Washington Publication Services, PP.78

N.O. Adedipe, M.K.C. Sridhar, and Joe Baker, 2005, Ecosystems and Human Well-Being Policy Responses, Chapter 10: Waste Management, Processing and Detoxification, Millennium Ecosystem Assessment Series, Edition 1, Island Press, PP.313-334

Olar Zerbock, and M.S. Candidate, 2003, Urban Solid Waste Management: Waste Reduction in Developing Nations, Requirements of CE 5993 Field Engineering in the Developing World, School of Forest Resources \& Environmental Science, Michigan Technological University, PP: 2-21

Sefouhi Linda, Mahdi Kalla, and Leila Aouragh, 2010, Trends and Problems of Municipal Solid Waste Management in Batna City and Prospects for a Sustainable Development, Int. J. of Sustainable Water \& Environmental Systems, Vol: 1, No: 1, PP.15-20

Ulrich Wieland \& Cees Van Beusekom, 2002, Municipal waste management in accession countries, European Communities, and Luxembourg Office for Official Publications of the European Communities, Belgium.

Wenke Hansen, Maria Christopher and Maic Verbuecheln, 2002, EU Waste Policy and Challenges for Regional and Local Authorities, Background Paper for the Seminar on Household Waste Management, "Capacity Building on European Community's Environmental Policy", Published by Ecologic, Institute for International and European Environmental Policy 